\title{
Anti Urolithiatic and Anti-Arthritis Activity of Various Extracts of Ganoderma lucidum
}

M Amin Mir ${ }^{1^{\star}}$, Taruna Sharma ${ }^{1}$, Kiran Sharma ${ }^{1}$, Saima Anjum ${ }^{1}$ and Bilal Ahmad Mir

${ }^{1}$ Sai Institute of Paramedical and Allied Sciences, Dehradun, India

${ }^{2}$ Uttaranchal (PG) College of Biomedical Sciences and Hospital, Dehradun, India

*Corresponding author: Amin Mir M, Sai Institute of Paramedical and Allied Sciences, Dehradun, India, Tel: 91-9897635334; E-mail: mohdaminmir@gmail.com

Received: October 05, 2017; Accepted: October 11, 2017; Published: October 16, 2017

Copyright: ( 2017 Amin Mir M, et al. This is an open-access article distributed under the terms of the Creative Commons Attribution License, which permits unrestricted use, distribution, and reproduction in any medium, provided the original author and source are credited.

\begin{abstract}
Ganoderma lucidum fungi extracts had been analysed for the Anti-urolithiatic and Anti-arthritis Activity, in which the observed results show that the concerned fungi extracts posses a good effect against urolithiatic and arthritis problems. The anti-urolithiatic activity of the extracts had been carried out in which the percentage decomposition of the calcium oxalate was analysed by the application of various extracts of the concerned fungi. Among the various extracts of the fungi it had been found that the DMSO extract of the fungi had been found to be more potent for the decomposition of the calcium stone and the decomposition percentage had been found to be $92.10 \%$ followed by Acetone extract $(91.52 \%)$. The least anti-urolithiatic activity was observed for the water extract of the fungi (89.76\%). Also the anti-arthritis activity of the fungi extracts had been carried via the inhibition of protein denaturation which is the main cause of arthritis. Although the renaturation of the proteins is not possible but further denaturation can be stopped by the application of various extracts of the concerned fungi so the arthritis problem can be stopped. From the analysed extracts of the concerned fungi it had been found that the acetone extract posses the highest inhibition of protein denaturation compared to water and DMSO extracts. The analysis had been carried out in reference to acetylsalicylic acid. The $\mathrm{IC}_{50}$ values of various extracts of the fungi and the reference compound had been found to be $32.5,56,40$, and 50.5 respectively for Acetylsalicylic acid, Acetone Extract, DMSO extract and water extract respectively. So as per the results of the above study are taken into consideration, the concerned fungi can be used for the diseases in reference.
\end{abstract}

Keywords: Food value; Anti urolithiatic; Anti arthritis; Ganoderma lucidum

\section{Introduction}

In recent years, natural products have been used extensively for discovery and development of new drugs [1]. A strong evidence confirmed from the data collected shows that natural products likes fruits, vegetables, herbs, cereals, and edible mushrooms are associated with less risk of many diseases [2]. Mushrooms have been extensively used throughout the world both as food and medicine for thousands of years. Mushrooms represent the world's major untapped source of potent pharmaceutical products having profound effect on humans. So a common line is being used as "medicines and food have a common origin" [3]. It is nearly estimated that there are nearly 1.5 million fungal species in world, of which approximately 82,000 have been mentioned [4]. Among the known species most of these belong to macro fungi, of which about 5,000 are edible and 2,000 safe for consumption [5]. Basidiomycota divisions of fungi are of great interest because they contain a large number of biological active compounds [6].

Traditionally, Ganoderma had been used from times immoral and is claimed to reduce the ill effect of various diseases and virtually cure all types' diseases [7-9]. Ling Zhi encompassed several Ganoderma species, which been widely used for medicinal purposes eg., Ganoderma lucidum, Ganoderma luteum steyaert, Ganoderma atrum Zhao, $\mathrm{Xu}$ and Zhang, Ganoderma applanatu (pers.:Wallr) pat.,Ganoderma australe (Fr.) pat., Ganoderma capense (Lloyd) Teng,
Ganoderma tropicum (Jungh) Bres.,Ganoderma tenue Zhao, Xu and Zhang and Ganoderma sinense Zhao, Xu and Zhang. More over World widely 250 Ganoderma species have been discovered [9,10], but for therapeutic use and literature citation, Ganoderma usually refers to the species of Ganoderma lucidum.

\section{Materials and Methods}

The Ganoderma lucidum was collected from FRI Dehradun. The fungi were shade dried and powdered in to mixture. All the chemicals used were of analytical grade.

\section{Extraction procedure for Ganoderma lucidum}

50 gms of the fungi material powder were weighed separately and accurately and then extracted in a Soxhlet Apparatus using thimble in order to get the best extract. Only two solvents were used depending upon their polarity index with increasing polarity (Acetone, DMSO, Water).

\section{Extraction A}

The sample was extracted with a particular solvent (like DMSO) in a Soxhlet apparatus, till no extract was coming out of the sample, as being examined by taking a small amount of the extracted solvent from the main chamber of the Soxhlet apparatus over the watch glass till no precipitate formation occurred there, on the watch glass. After the Extraction with acetone, the extract solution was subjected to filtration to remove the residue from extract. The filtrate was collected and evaporate to remove the volatile solvent to its $1 / 4$ volume on water 
bath at a suitable temperature. The whole filtrate was then made in solid form (powdered) after being kept in an oven. Then the residue was collected.

\section{Extraction B}

The residue from the first was treated in the same manner for extraction by using DMSO.

\section{Extraction C}

The residue was then extracted with water by decoction technique. The residue so for obtained was dissolved in nearly 500 of water and was boiled for time period up to which the water was absorbed. Then after another in the same residue another $500 \mathrm{ml}$ of water was added and boiled to $1 / 2$ of its original volume. Finally the extract was cooled and filtered first by ordinary filter paper and finally through whatman filter paper. The filtrate so obtained was evaporated to $1 / 4$ of its original volume. The whole filtrate was then made in solid form (powdered) after being kept in an oven. Then the residue was collected.

\section{Anti-arthritis activity determination of Ganoderma lucidum by Deshpande Jadhav VM and Kadam V J. 2009 [11]}

The reaction mixture $(0.5 \mathrm{ml})$ consisted of $0.45 \mathrm{ml}$ bovine serum albumin (5\% aqueous solution) and $0.05 \mathrm{ml}$ of Ganoderma lucidum extracts (100 and $250 \mathrm{mcg} / \mathrm{ml}$ of final volume). $\mathrm{pH}$ was adjusted at 6.3 using a small amount of $1 \mathrm{~N} \mathrm{HCl}$. The samples were incubated at $37^{\circ} \mathrm{C}$ for $20 \mathrm{~min}$ and then heated at $57^{\circ} \mathrm{C}$ for $30 \mathrm{~min}$. After cooling the samples, $2.5 \mathrm{ml}$ phosphate buffer saline ( $\mathrm{pH} 6.3$ ) was added to each tube. Turbidity was measured spectrophotometrically at $660 \mathrm{~nm}$ for control test $0.05 \mathrm{ml}$ distilled water was used instead of extracts while product control test lacked bovine serum albumin. The percentage inhibition of protein denaturation was calculated as follows.

Percent inhibition $=100-($ O.D. of test-O.D. of product control) $\times$ $100 /$ OD of control

The control represents $100 \%$ protein denaturation. The results were compared with acetyl salicylic acid $(250 \mathrm{mcg} / \mathrm{ml})$ treated samples.

\section{In vitro Anti-urolithiatic activity of extracts}

\section{Estimation of calcium oxalate by titrimetry $[12,13]$}

Preparation of calcium oxalate by homogenous precipitation: By taking equimolar solution of Calcium chloride di-hydrate (A.R) was dissolved in distilled water and Sodium oxalate (A.R) was dissolved in $10 \mathrm{ml}$ of $2 \mathrm{~N} \mathrm{H}_{2} \mathrm{SO}_{4}$ and distilled water, sufficient quantity is allowed to react in a beaker. The resulting precipitate was calcium oxalate which was freed from traces of sulphuric acid by ammonia solution. Washed with distilled water and dried at a temperature $60^{\circ} \mathrm{C}$ for 4 hours.

Preparation of the semi permeable membrane from farm eggs: The outer calcified shell was removed chemically by placing the eggs in 2 ml HCL for overnight, which caused complete decalcification. Further, washed with distilled water and carefully with a sharp pointer a hole is made on the top and the contents squeezed out completely from the decalcified egg. Washed thoroughly with distilled water and placed it in ammonia solution, in the moistened condition for a while and then rinsed it with distilled water. Stored in refrigerator at a $\mathrm{pH}$ of 7-7.4.

Method: Weighed exactly $1 \mathrm{mg}$ of the calcium oxalate and $10 \mathrm{mg}$ of the n-hexane extract, ethanolic extract, water extract, isolated compound and standard cystone were packed it together in semi permeable membrane by suturing. They were allowed to suspend in a conical flask containing $100 \mathrm{ml} 0.1 \mathrm{M}$ TRIS buffer. One group served as negative control (contained only $1 \mathrm{mg}$ of calcium oxalate). Placed the conical flask of all groups in a incubator, pre heated to $37^{\circ} \mathrm{C}$ for 2 hours, for about 7-8 hours. Removed the contents of semi- permeable membrane from each group into a test tube and added $2 \mathrm{ml}$ of $1 \mathrm{~N}$ sulfuric acid and titrated with $0.9494 \mathrm{~N} \mathrm{KMnO}_{4}$ till a light pink color end point obtained. $1 \mathrm{ml}$ of $0.9494 \mathrm{~N} \mathrm{KMnO}_{4}$ equivalents to $0.1898 \mathrm{mg}$ of Calcium oxalate breakdown. Finally the percentage of dissolution of calcium oxalate by various groups was calculated.

Estimation of calcium phosphate by colorimetry: Preparation of Calcium phosphate by homogenous precipitation by taking equimolar solution of Calcium chloride dihydrate (A.R) dissolved in distilled water and Disodium hydrogen phosphate (A.R) dissolved in $10 \mathrm{ml}$ of ( $2 \mathrm{~N} \mathrm{H}_{2} \mathrm{SO}_{4}$ ) and distilled water. The resulting precipitate was calcium phosphate which was freed from traces of sulfuric acid by ammonia solution. Washed with distilled water and dried at a temperature $60^{\circ} \mathrm{C}$ for 4 hours.

\section{Observations and Results}

\section{Anti-urolithiatic activity of various extracts of Ganoderma lucidum}

Behind this activity the idea was to know the role of plant extract in dissolving the already formed stones nucleus in renal system. For this artificial calcium oxalate crystal were prepare in the laboratory by standard method. Also semi permeable membrane was prepared from egg using standard methods (Tables 1-4; Figures 1-4).

\section{Anti-arthritis activity of Ganoderma lucidium}

The Anti-arthritis activity of various Ganoderma lucidium extracts Viz (Acetone, DMSO and Water) have been analyzed, and it was found that (DMSO extract) posses the highest anti-arthritis activity followed by (water extract). The percentage inhibition by plant extracts was found to be concentration dependent, percentage inhibition increases with the increase in the concentration of the plant extracts. The IC50 value was determined from the straight line graph. The IC50 value of all the plant extracts was found lesser than the reference compound (acetyl salicylic acid). The IC50 value of various plant extracts follows the order (DMSO extract, Water extract and finally Acetone Extract) was found to be $(40,50.5,56)$ respectively and are presented in (Tables).

\begin{tabular}{|l|l|l|l|l|l|}
\hline S. No. & Plant Extract & Conc. of plant extract & $\begin{array}{l}\text { Weight of } \\
\text { calcium oxalate }\end{array}$ & $\begin{array}{l}\text { Un-decomposed } \\
\text { calcium oxalate }\end{array}$ & $\begin{array}{l}\text { Decomposed calcium } \\
\text { oxalate }\end{array}$ \\
\hline 1 & Acetone extract & $1000 \mathrm{mg}$ & 1 & 0.0848 & 0.9152 \\
decomposed
\end{tabular}


Citation: Amin Mir M, Sharma T, Kiran Sharma K, Saima Anjum S, Bilal Ahmad M (2017) Anti Urolithiatic and Anti-Arthritis Activity of Various

3

Water extract

$1000 \mathrm{mg}$

1

0.1024

0.8976

$89.76 \%$

Table 1: Showing the Anti-urolithiatic property of various extracts of Ganoderma lucidum.

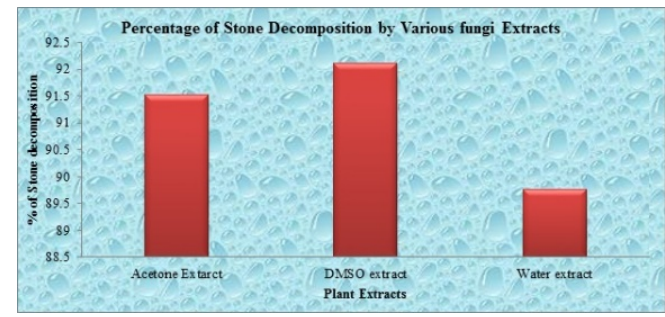

Figure 1: Showing the Anti-urolithiatic property of various extracts of Fungi.

\begin{tabular}{|l|l|l|l|l|}
\hline S. No & Conc. $\boldsymbol{\mu g} / \mathbf{m l}$ & Absorbance & $\%$ Red & \multirow{2}{*}{ IC $_{50}$ Value } \\
\hline 1 & 20 & 0.545 & 39.61 & \\
\cline { 1 - 3 } & 40 & 0.456 & 57.12 & \\
\cline { 1 - 3 } & 60 & 0.312 & 71.11 & \\
\cline { 1 - 3 } & 80 & 0.198 & 85.43 & \multirow{2}{*}{32.5} \\
\hline 5 & 100 & 0.071 & 92.17 & \\
\hline
\end{tabular}

Table 2: Showing Anti-arthritis activity of acetyl salicylic acid Standard.

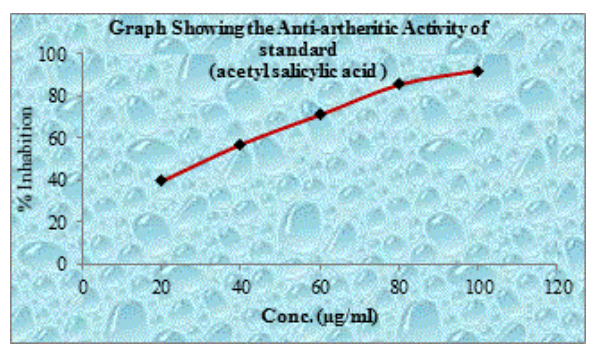

Figure 2: Showing Anti-arthritis Activity of Standard (acetyl salicylic acid).

\begin{tabular}{|c|c|c|c|c|}
\hline S. No & Conc. $\mu \mathrm{g} / \mathrm{ml}$ & Absorbance & $\%$ Red & $\mathrm{IC}_{50}$ Value \\
\hline 1 & 20 & 0.855 & 11.81 & \\
\hline 2 & 40 & 0.651 & 34.62 & \\
\hline 3 & 60 & 0.461 & 53.41 & \\
\hline 4 & 80 & 0.451 & 54.35 & \\
\hline 5 & 100 & 0.322 & 67.72 & 56 \\
\hline
\end{tabular}

Table 3: Showing Anti-arthritis activity of Acetone extract of Ganoderma lucidum.

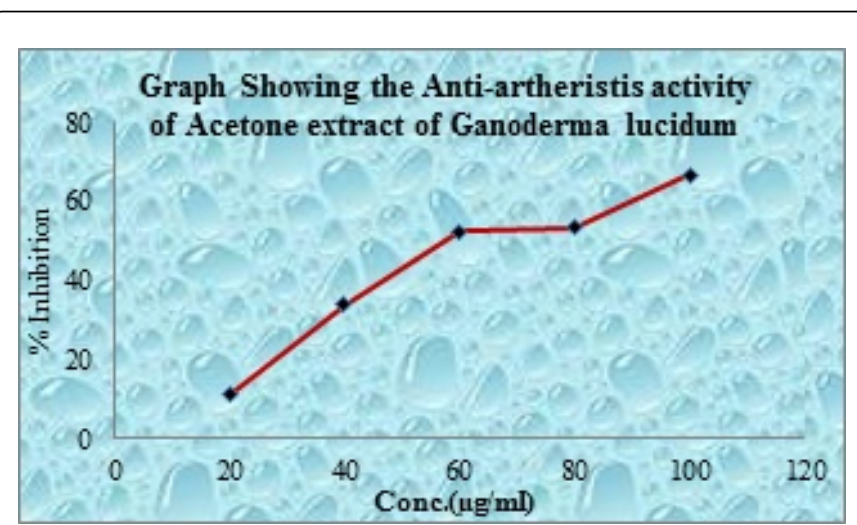

Figure 3: Showing the Anti-arthritis Activity of Acetone extract of Ganoderma lucidum.

\begin{tabular}{|c|c|c|c|c|}
\hline S. No & Conc. $\mathrm{g} / \mathrm{ml}$ & Absorbance & $\%$ Red & $\mathrm{IC}_{50}$ Value \\
\hline 1 & 20 & 0.7825 & 38.14 & \\
\hline 2 & 40 & 0.442 & 48.27 & \\
\hline 3 & 60 & 0.24 & 72.21 & \\
\hline 4 & 80 & 0.212 & 71.43 & \\
\hline 5 & 100 & 0.071 & 89.37 & 40 \\
\hline
\end{tabular}

Table 4: Showing Anti-arthritis activity of DMSO extract of Ganoderma lucidum.

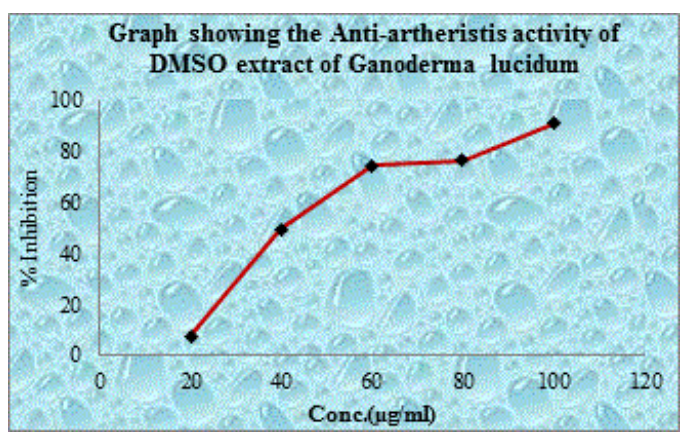

Figure 4: showing the Anti-arthritis activity of DMSO extract of Ganoderma lucidum.

\begin{tabular}{|l|l|l|l|l|}
\hline S. No & Conc. $\mathbf{g} / \mathbf{m l}$ & Absorbance & $\%$ Red & IC $_{50}$ Value \\
\hline 1 & 20 & 0.671 & 28.16 & \\
\hline 2 & 40 & 0.526 & 45.15 & \\
\cline { 1 - 2 } & 60 & 0.445 & 51.5 & \multirow{2}{*}{50.5} \\
\hline
\end{tabular}




\begin{tabular}{|l|l|l|l|l|}
\hline 4 & 80 & 0.252 & 71.6 & \\
\cline { 1 - 4 } 5 & 100 & 0.105 & 88.27 & \\
\hline
\end{tabular}

Table 5: Showing Anti-arthritis activity of Water extract of Ganoderma lucidum.

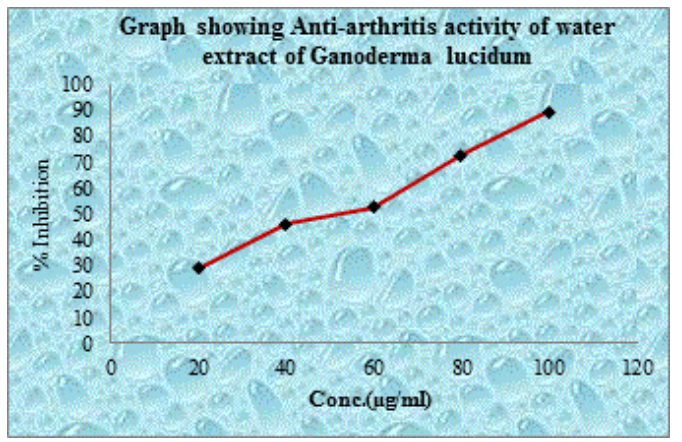

Figure 5: Showing the Anti-arthritis activity of Water extract of Ganoderma lucidum.

\section{Discussion}

The kingdom fungi is very interesting, because it furnishes all the types of metabolites which are very useful for the continuity of life, and for good health in addition helps in making our environment clean.

Protein denaturation or arthritis is a process in which proteins lose their tertiary structure and secondary structure by application of external stress or compound, such as strong acid or base, a concentrated inorganic salt, an organic solvent or heat. Most biological proteins lose their biological function when denatured. For example, enzymes lose their activity, because the substrates can no longer bind to the active site. Denaturation of protein is one of the causes of rheumatoid arthritis as has been documented. Production of auto antigen leads to denaturation of protein in certain arthritic disease. This anti-denaturation effect was further supported by the change in viscosities. It has been reported that the viscosities of protein solutions increase on denaturation. From the result of the present study, it can be stated that all the extracts of Ganoderma lucidum are capable of controlling the production of auto - antigen and thereby it inhibit the denaturation of proteins of both fresh egg albumin and bovine albumin in dose dependent manner and its effect was compared with the standard drug acetyl salicylic acid. DMSO extract of Ganoderma lucidum have pronounced effect against arthritis, followed by water and acetone extracts.

The work was performed by using in vitro anti-urolithiatic model for calculating percentage dissolution of kidney stone. This study has given primary evidence for Ganoderma as the fungi which possess lithiasis property. More specifically we can conclude from the results that Acetone and DMSO extracts both showing good anti urolithiasis activity. From the Table it is also clear that positive correlation exists between individual extracts and concentration used in the study. Out of various concentration used we can observe that activity increase as we increase the concentration and at one point further no increase in the activity observed. The fungi used in the above study also showing good activity when it was compared with the standard drug. The
DMSO extract has been found to be more potent in terms of activity compare to Acetone and water. The above work recommends the fungi extract for the further studies by conducting in-vivo model.

\section{Conclusion}

The present set up of life, which is totally industrially based have so many ill effects against the human life. One among them is the stone problem in kidneys and in gall bladder, which is simply due to the utilization of chemical substances in the water bodies to kill microorganisms and other disease producing organisms. But these chemical substances by one way or another way find their entry into the human systems. Also among the humans the male generates are more prone to kidney stone related problems than the female generates, because of the biological differences in the two generates. In the presents efforts have been made to find some solution against the removal of kidney stone, whose ultimate cure is to operate a kidney for the removal of stone from it. The process of kidney operation is costly and is not out of danger. So from the present study many fungi extracts have been found cost effective against the removal of stone from the kidney, in which some measure have been made to make the breakdown of stone within the kidney and is then easily removed via urine.

Anti-arthritic effect of various extracts of Ganoderma lucidum" was studied significantly by using in-vitro inhibition of protein denaturation model. The effect against the inhibition of protein denaturation was carried out by utilizing various extracts of Ganoderma lucidum". All the extracts had been found to be concentrations (dose levels) provided significant protection against denaturation of proteins. Most of the investigators have reported that denaturation of protein is one of the cause of rheumatoid arthritis. Production of auto-antigens in certain rheumatic diseases may be due to in vivo denaturation of proteins. Mechanism of denaturation probably involves alteration in electrostatic, hydrogen, hydrophobic and disulphide bonding. Obtained data suggests that the fungi in reference could be used as potent anti-arthritic agent.

\section{References}

1. Qing-Ping W, Yi-Zhen X, Sen-Zhu L, David La P, Zhaqun D, et al. (2006) Tumor cell adhesion and integrin expression affected by Ganoderma lucidum. Enzyme Microbial Technol 40: 32-41.

2. Block G, Patterson B, Subar A (1992) Fruit, vegetables and cancer prevention: a review of the epidemiological evidence. Nutr Cancer 18: $1-29$.

3. Kaul TN (2001) Biology and conservation of mushrooms. Oxford and IBH Publishing Co. Pvt. Ltd. New Delhi, India, pp: 117-145.

4. Kirk PM, Cannon PF, David JC, Stalpers JA (2001) Ainsworth and Bisky's Dictionary of Fungi. 9th Wallingford, CAB International, UK.

5. Hawksworth DL (2001) Mushrooms: the extent of the unexplored potential. Int J Med Mushroom 3: 333-337.

6. Lorenzen K, Anke T (1998) Basidiomycetes as a source for new bioactive natural products. Curr Org Chem 2: 329-364.

7. Kingston DG, Newman DJ (2005) The search for novel drug lead for predominately antitumor therapies by utilizing Mother Nature's pharmacophoric libraries. Curr Opin Drug Discov Devel 8: 207-227.

8. Mizuno T (1995) Bioactive biomolecules of mushrooms: food function and medicinal effect of mushroom fungi. Food Rev Int 11: 7-21.

9. Moncalvo JM, Ryvarden L (1997) A Nomenclatural study of the Ganoderma taceae Donk, Synopsis fungorum 11, Fungiflora: Osle, Norway, p: 114.

10. Wasser SP, Weis AL (1997) Medicinal Mushrooms Ganoderma lucidum (Curtis: Fr). Peledfus Publ House, Haifa, Israel. 
Citation: Amin Mir M, Sharma T, Kiran Sharma K, Saima Anjum S, Bilal Ahmad M (2017) Anti Urolithiatic and Anti-Arthritis Activity of Various Extracts of Ganoderma lucidum. Nat Prod Chem Res 5: 297. doi:10.4172/2329-6836.1000297

Page 5 of 5

11. Deshpande V, Jadhav VM, Kadam VJ (2009) In-vitro anti-arthritic activity of Abutilon indicum (Linn.) Sweet. J Pharm Res 2: 644-645.

12. Garimella TS (1998) Invitro studies on antilithiatic activity of the seeds of Dolichosbiflorus Linn. and rhizomes of Bergenialigulata Wall.

13. Saso L, Valentini G, Leone MG, Grippa E (1998) Development of an in vitro assay for the screening of substances capable of dissolving calcium oxalate crystals. Urology Intern 61: 210-214.
14. Sakakura T, Fujita K, Yasui T, Sasaki D (1999) Calcium phosphate stones produced by Madin - Darby canine kidney (MDCK) cells inoculated in nude mice. Urology Res 279: 200-205. 